\title{
Seismic Performance of Precast Polystyrene RC Walls
}

\author{
Ari Wibowo ${ }^{1, *}$ \\ ${ }^{1}$ Department of Civil Engineering, Faculty of Engineering, Brawijaya University, Malang, 65149, \\ Indonesia
}

\begin{abstract}
Precast concrete structure such as precast wall is a concept that is growing rapidly these days. However, the earthquake resistance is believed to be one of its drawbacks. Additionally, the large weight of solid elements also increase the building weight significantly which consequently increase the earthquake base shear force as well. Therefore, investigation on the seismic performance of precast concrete wall has been carried out. Three RC wall specimens using wire mesh reinforcement and EPS (Extended Polystyrene System) panel have been tested. This wall was designed as a structural wall that was capable in sustaining lateral loads (in-plane) yet were lightweight to reduce the total weight of the building. Parameter observed was the ratio of height to width (aspect ratio) of wall of $1.0,1.5$ and 2.0 respectively with the aim to study the behaviour of brittle to ductile transition of the wall. Incremental static load tests were conducted until reaching peak load and then followed by displacement control until failure. Several data were measured at every stage of loading comprising lateral load-displacement behaviour, ultimate strength and collapse mechanism. The outcomes showed that precast concrete walls with a steel wire and EPS panel filler provided considerably good resistance against lateral load.
\end{abstract}

\section{Introduction}

Shear wall is one of the structural elements of the building functioning in restraining lateral loads such as earthquake excitation and severe wind forces by providing in-plane rigid stiffness of the walls. However, the solid and large weight of walls increase the total weight of building which in turn increase the total earthquake shear force as well, and hence reduce the effectiveness of wall at some extent. Therefore, reducing the self-weight of wall becomes quite important provided that the wall lateral strength capacity does not decrease too much.

One of the idea on minimizing self-weight of the wall is by using Extended Polystyrene (EPS, known as Styrofoam) as panel sandwiched between two steel wires. EPS is regarded as environmentally friendly material since it is fully recyclable and reusable made of plastic. EPS is also fire-proof and commonly used as insulated material and hence increases the fire resistant of the building. In terms of construction method, EPS is better used in

* Corresponding author: ariwibowo@ub.ac.id 
precast system rather that cast in-situ due to the simplicity in the manufacturing and on-site construction processes. Investigations on existing precast building showed that such system were interestingly able to provide large lateral drift capacity [1], despite that precast systems are commonly believed to have low resistance capacity against lateral loads such as earthquake excitation. Therefore, the experimental test has been conducted to investigate the overall seismic performance of such walls.

$\mathrm{RC}$ walls can be categorised into three groups. $\mathrm{RC}$ walls with aspect ratios less or equal than 1.0 are commonly called as short walls which generally develop in-plane strut-and-tie mechanism to resist lateral forces. For aspect ratios of RC walls higher than 2.0, the RC walls will possess low Flexural-to-Shear Strength Ratio $(\mathrm{FSSR}=M / L V$ ) which tend to develop dominant flexural action and hence are called slender walls. The displacement capacities of high-rise shear walls tend to be higher than short walls with the flexural failures occur at the wall base; whilst on contrary, the failure mode of short walls is mainly dominated by shear mechanism with the crack patterns display shear failure only. For midrise $\mathrm{RC}$ walls, the seismic behaviour is a combination of both flexure and shear.

For squat $\mathrm{RC}$ wall $\left(H_{w} / L_{w} \leq 1.0\right)$, the interaction between shear and flexural capacity is more dependant to each other compared to that of tall $\mathrm{RC}$ walls. The behaviour of lateral load-deformation of squat RC walls resembles with that of deep beam, where on contrary, tall RC walls behave in flexural-dominant manner which are quite similar to columns. Another difference between squat and tall RC walls is in the context of gravity load. Lowrise $\mathrm{RC}$ walls commonly sustain only small gravity loads which in turn provides less effect on shear strength capacity. It is safe to ignore the axial load in shear strength capacity calculation for squat RC walls. But this case might not be applied for tall $\mathrm{RC}$ walls that carry much larger gravity load. For squat RC walls, the requirement of vertical reinforcement may not be necessarily large since squat $\mathrm{RC}$ walls possess longer lever arm with small gravity and lateral forces. And thus vertical reinforcement can be distributed uniformly over the full length of the wall, permitting only marginal increment at the vertical edges without losing too much ductility [2]

The purpose of this study was to determine the maximum lateral strength capacity and the lateral load-drift behaviour of EPS RC walls with various aspect ratios when subjected to lateral load. Moreover, the collapse mechanism in the context of the flexural-to-brittle behaviour of EPS walls was of particular interest. Therefore, the specimens were designed by varying ratio of height to width $\left(\mathrm{H}_{\mathrm{w}} / \mathrm{L}_{\mathrm{w}}\right)$ of the wall to investigate the effect of aspect ratio to the collapse mechanism; whilst, other parameters such as vertical and horizontal rebars were set in constant.

\section{Experimental test program}

Parameters affecting the lateral load-drift behaviour of beam-column elements such as RC columns/walls are axial load ratio, aspect ratio, longitudinal reinforcement ratio and lateral reinforcement ratio. It was observed that for slender $\mathrm{RC}$ walls, the ultimate drift capacity increases by decreasing axial load ratio and by increasing transverse steel ratio and aspect ratio. However, the overall trends indicate that some parameters have some interdependence - particularly on the aspect ratio and the longitudinal steel ratio [3]. In this study, the aspect ratio of $\mathrm{RC}$ wall has been further investigated.

The experimental tests on three RC wall specimens S1-S3 have been conducted with wall heights of $60 \mathrm{~cm}, 90 \mathrm{~cm}$ and $120 \mathrm{~cm}$, which corresponds to aspect ratio of 1.0, 1.5 and 2.0 respectively. The $\mathrm{RC}$ wall specimens were detailed with steel wire (wire mesh) placed on each side of the $4 \mathrm{~cm}$ thick EPS panel in the core of the concrete wall and connected to each other by $\phi 3.0 \mathrm{~mm}$ wire connectors. The main reinforcement were $\phi 2.5 \mathrm{~mm}$ galvanized steel wires at $75 \mathrm{~mm}$ spacing vertically and horizontally with yield and ultimate tensile 
strengths of $600 \mathrm{MPa}$ and $680 \mathrm{MPa}$ respectively. The RC wall specimens used two layers of concrete plaster on outer side of walls with thickness of $70 \mathrm{~mm}$ (about 1.4 inch) and concrete strength of $15 \mathrm{MPa}$. The typical RC wall specimens were shown in Fig 1.

Table 1. Basic Property of Column Specimens

\begin{tabular}{|c|c|c|c|c|c|}
\hline \multirow{2}{*}{ Specs. } & \multirow{2}{*}{$\begin{array}{c}\text { Width } \\
\text { (cm) }\end{array}$} & \multirow{2}{*}{$\begin{array}{c}\text { Height } \\
(\mathrm{cm})\end{array}$} & \multirow{2}{*}{$\begin{array}{c}\text { Aspect ratio } \\
\text { (L/D) }\end{array}$} & \multicolumn{2}{|c|}{ Reinforcement } \\
\hline & & & & Vertical & Horisontal \\
\hline S1 & 60 & 60 & 1.0 & $\phi 2.5-75$ & $\phi 2.5-75$ \\
\hline $\mathrm{S} 2$ & 60 & 90 & 1.5 & $\phi 2.5-75$ & $\phi 2.5-75$ \\
\hline S3 & 60 & 120 & 2.0 & $\phi 2.5-75$ & $\phi 2.5-75$ \\
\hline
\end{tabular}

The RC wall specimens were tested using a static load testing procedure to obtain representative lateral load versus displacement curves. The load controlled loading sequence consisted of load increments of $1 \mathrm{kN}$ until reaching peak load, and then followed by drift increment of $0.5 \%$ until failure.

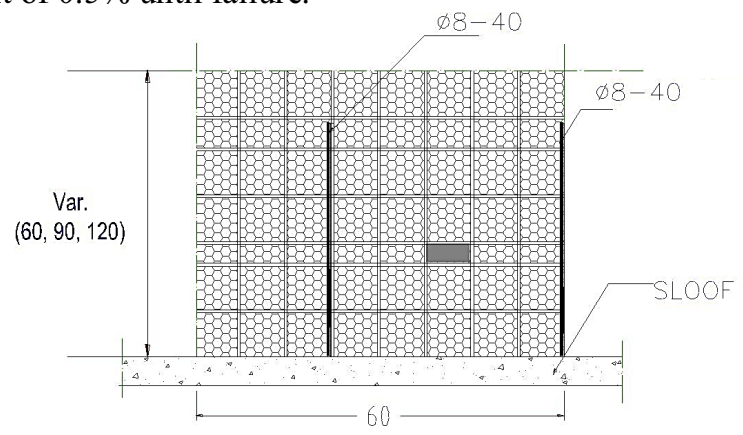

Fig. 1. Geometry and reinforcement details of RC wall specimens

\section{Lateral load-displacement behaviour}

As shown in Fig. 2a and Table 2, specimen S1 $(a=1.0)$ provided highest peak load but showing quite brittle behaviour with displacement ductility $\left(\mu=\Delta_{\mathrm{u}} / \Delta_{\mathrm{y}}\right)$ of about 1.7 . On the other hand, specimen S3 $(a=2.0)$ could sustain lateral load at the largest ductility of 5.7 but had the least peak load capacity compared to those of other specimens with smaller aspect ratios. Further, specimen S2 $(a=1.5)$ had both peak load and ductility ratio in between of those of specimens $\mathrm{S} 1$ and $\mathrm{S} 3$. Furthermore, the related drift $(\delta=\Delta / \mathrm{H})$ behaviour for all specimens is shown in Fig. $2 b$.

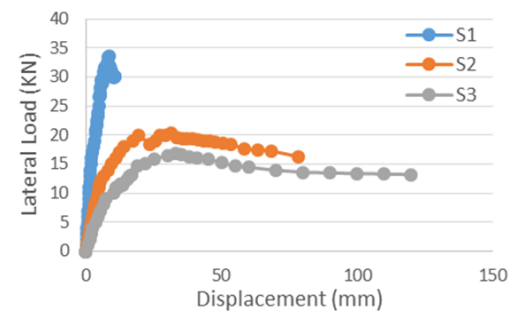

a. Lateral load-displacement behaviour.

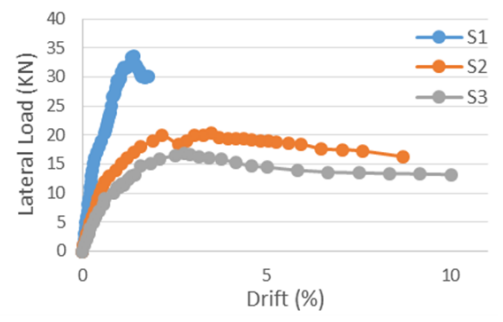

b. Lateral load-drift behaviour.

Fig. 2. Relationship between lateral load and displacement/drift for all specimens. 
Table 2. Peak Load and displacement behaviour of specimens S1-S3.

\begin{tabular}{|c|c|c|c|c|}
\hline Specimen & $\begin{array}{c}\text { Peak Load, } \\
\mathbf{P}_{\mathbf{u}} \\
(\mathbf{k N})\end{array}$ & $\begin{array}{c}\text { Yield } \\
\text { Displacement, } \\
\boldsymbol{\Delta}_{\mathbf{y}} \\
(\mathbf{m m})\end{array}$ & $\begin{array}{c}\text { Displacement at } \\
\text { lateral load } \\
\text { failure, } \boldsymbol{\Delta}_{\mathbf{u}} \\
(\mathbf{m m})\end{array}$ & $\begin{array}{c}\text { Displacement } \\
\text { ductility } \\
\boldsymbol{\mu}=\Delta_{\mathbf{u}} / \Delta_{\mathbf{y}}\end{array}$ \\
\hline S1 & 33.6 & 6.4 & 10.7 & 1.7 \\
\hline S2 & 20.4 & 15 & 77 & 5.1 \\
\hline S3 & 16.8 & 21 & 120 & 5.7 \\
\hline
\end{tabular}

\section{Collapse mechanism}

There are three categories of failure commonly defined for RC walls under lateral load, i.e., flexure-critical, shear-critical, and flexure-shear-critical as shown in Fig. 3. A flexurecritical RC wall is one that has sufficient shear strength to develop flexural yielding, whilst a shear-critical wall is one that fails in shear, with the corresponding moment demand significantly less than the moment capacity. A flexure-shear-critical $\mathrm{RC}$ wall is one that yields in flexure prior to failing in shear at higher ductility levels.

The failure mechanism can be predicted by calculating the flexural-to-shear strength ratio (FSSR) as stated in Equation (1) and using Table 3. It should be noted that the classification system was developed by the ASCE for columns/walls detailed for ductility and hence may not be directly applicable to limited ductile $\mathrm{RC}$ walls.

$$
F S S R=\frac{M_{n}}{L V_{n}}
$$

where;

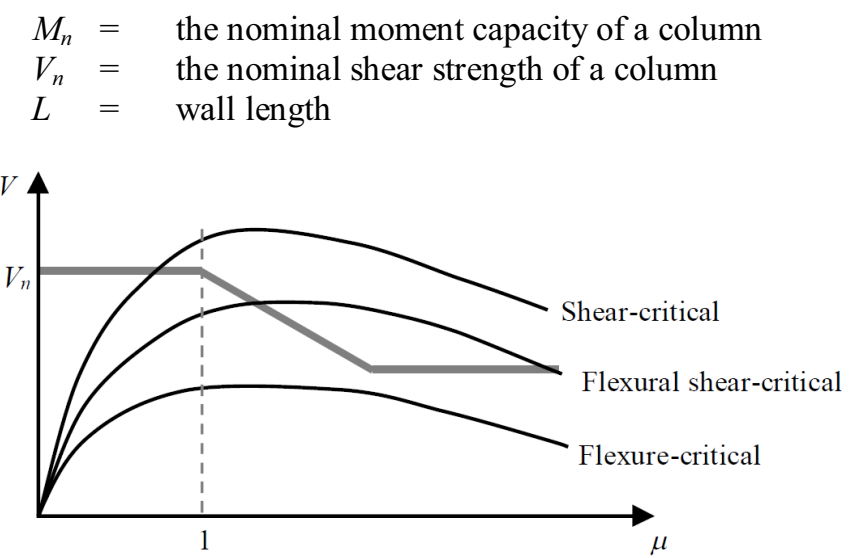

Fig. 3. Shear strength degradation and displacement ductility.

Table 3. Classification of Failure Mechanism (Refer [4], SECTION 6.4.2.2.2).

\begin{tabular}{|c|c|c|c|}
\hline & \multicolumn{3}{|c|}{ Transverse Reinforcement Details } \\
\hline & $\begin{array}{c}\text { ACI conforming } \\
\text { details with } \mathbf{1 3 5}^{\mathbf{0}} \\
\text { hooks }\end{array}$ & $\begin{array}{c}\text { Closed hoops with } \\
\mathbf{9 0}^{\mathbf{0}} \text { hooks }\end{array}$ & $\begin{array}{c}\text { Other (including lap } \\
\text { spliced transverse } \\
\text { reinforcement) }\end{array}$ \\
\hline$F S S R \leq 0.6$ & Flexure & Flexure-shear & Flexure-shear \\
\hline $0.6<F S S R \leq 1.0$ & Flexure-shear & Flexure-shear & Shear \\
\hline$F S S R>1.0$ & Shear & Shear & Shear \\
\hline
\end{tabular}


All RC wall specimens developed first flexural crack at wall-foundation interface producing gap opening between wall and foundation, which indicated that yield penetration mechanism occurred. Additionally, as the number of load cycle increased towards peak lateral strength, several vertical cracks at bar locations also penetrated deeper into the sloof foundation showing the development of bond slip failure between steel bars and the surrounding concrete. Specimen S1 $(a=1.0)$ showed shear-dominant cracks with main diagonal shear crack extending from lateral load point at the tip of the wall to the corner of compression zone of concrete at the bottom of the wall specimen. On contrary, the propagation of flexural-shear cracks were localised at the plastic hinge area of specimen S3 $(a=2.0)$, with no cracks found at the elastic area outside the plastic zone. Whereas, for specimen S2 $(a=1.5)$ those flexural-shear cracks were observed at a larger extent up to the top of wall specimen. The crack propagation patterns for all specimens are shown in Figure 4.

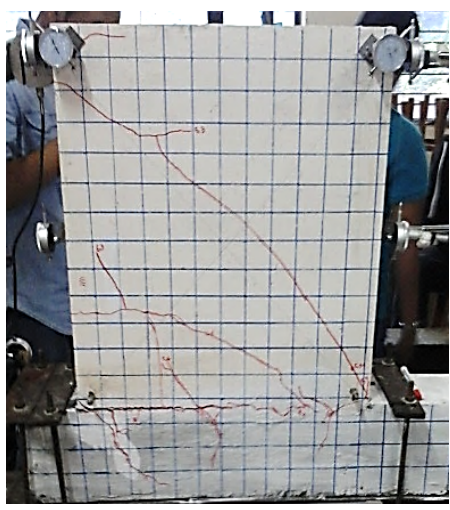

a. Specimen $\mathrm{S} 1(\mathrm{a}=1.0)$

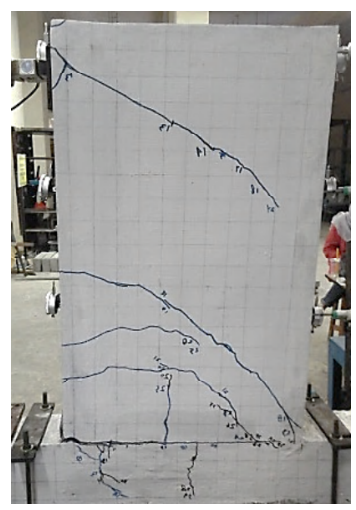

b. Specimen $\mathrm{S} 2(\mathrm{a}=1.5)$

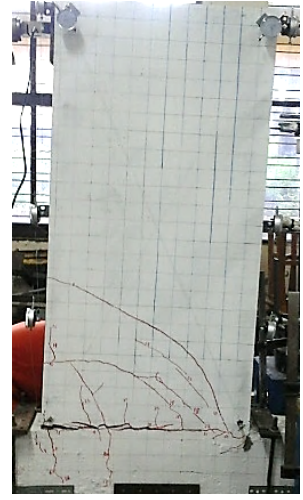

c. Specimen $\mathrm{S} 3(\mathrm{a}=2.0)$

Fig. 4. Crack propagation over the height of specimens.

The two main shear failure mechanisms of a reinforced concrete elements are shearcompression failure and diagonal tension failure. Shear-compression failure occurs due to arch action causing crushing of concrete along the diagonal strut which usually takes place for cases of RC walls with a very high axial load (i.e. above the balance point) or relatively low shear span ratio (i.e. $a<2$ ). For diagonal tension failure, tensile stresses in the concrete governs the failure mechanism by causing the inclined cracks to become unstable and expand through the compression area; where it tends to occur when the axial load is below the balance point and the aspect ratio of the column is larger than $2(a>2)$. The tested specimens S1-S3 (aspect ratios $a<2$ with no axial load applied) were categorized inbetween those two conditions, but however, the test results showed that all specimens seems to be dominated by diagonal tension failure. It indicated that axial load ratio provides greater effect than the aspect ratio on shear failure mechanism of short RC walls $(a<2)$.

With the calculated nominal moment and shear capacity of the RC wall of $26.5 \mathrm{kNm}$ and $53.4 \mathrm{kN}$ respectively, the predicted failure mechanisms of $\mathrm{RC}$ wall are shear dominated for specimen S1 $(\mathrm{a}=1.0)$ and flexure-shear dominated for specimens S2 and S3 which are in good agreement with the test results as shown in Table 4.

The lateral displacement of walls $\left(\Delta_{t o t}\right)$ consists of three components, flexural $\left(\Delta_{f l}\right)$, yield penetration $\left(\Delta_{y p}\right)$ and shear deformation $\left(\Delta_{s h}\right)$ as shown in Fig. 5 (refer [5]). As shown in Fig. 6, specimen S1 with the least aspect ratio of $a=1.0$ had the largest proportion of shear drift component of about $90 \%$ of the total lateral drift, and hence showed the dominant shear behaviour of wall as shown in Fig. 6a. In contrast, the flexural components were the 
most dominant behaviour for specimens S2 and S3 at around $75 \%-85 \%$ of the total drift due to the large aspect ratio of $a>1.5$ as shown in Fig. $6 b$.

$$
\Delta_{t o t}=\Delta_{f l}+\Delta_{y p}+\Delta_{s h}
$$

Table 4. Predicted and Actual Failure Mechanism for all specimens.

\begin{tabular}{|c|c|c|c|c|c|}
\hline \multirow{2}{*}{ Specimen } & \multirow{2}{*}{$\begin{array}{c}\text { Aspect } \\
\text { ratio }\end{array}$} & $\begin{array}{c}\text { Wall } \\
\text { height (m) }\end{array}$ & \multirow{2}{*}{ FSSR } & \multicolumn{2}{|c|}{ Failure Mechanism } \\
\cline { 4 - 6 } & 1.0 & 0.6 & 0.83 & Predicted & Shear \\
\hline S1 & 1.5 & 0.9 & 0.55 & Flexure-shear & $\begin{array}{c}\text { Flexure shear over wall } \\
\text { height }\end{array}$ \\
\hline S2 & 2.0 & 1.2 & 0.41 & Flexure-shear & $\begin{array}{c}\text { Flexure shear concentrated at } \\
\text { plastic hinge area }\end{array}$ \\
\hline
\end{tabular}

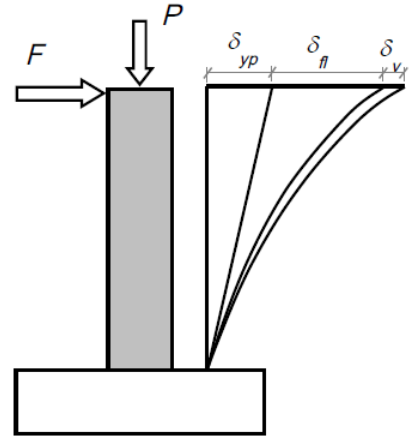

a. Reinforced concrete wall

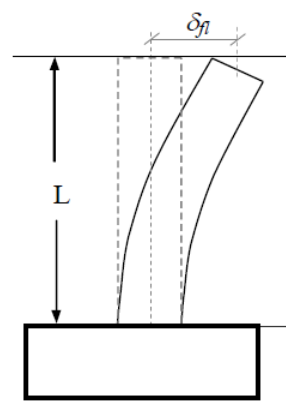

b. Flexural displacement

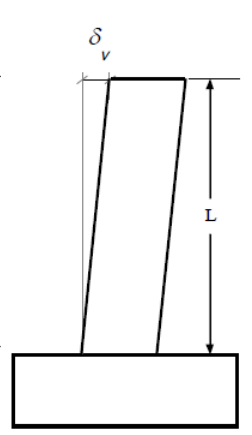

c. Shear displacement

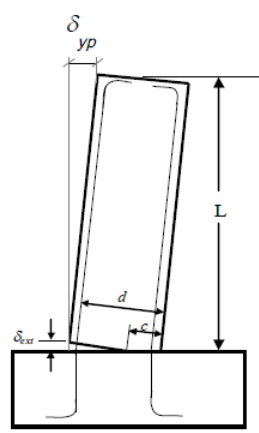

d. Yield penetration displacement

Fig. 5. Lateral displacement components of $\mathrm{RC}$ wall comprising flexural, shear and yield penetration displacement.

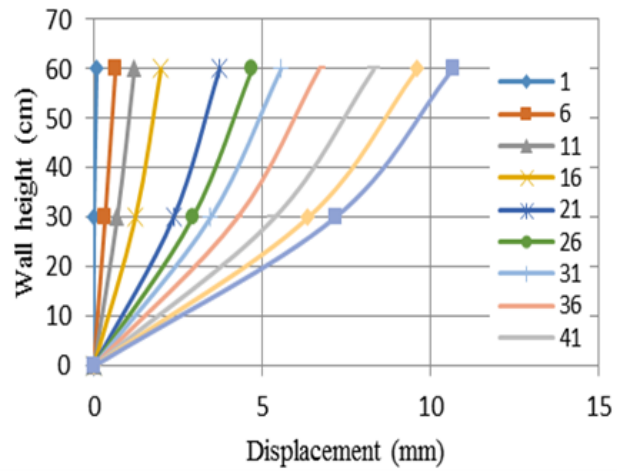

a. Specimen S1

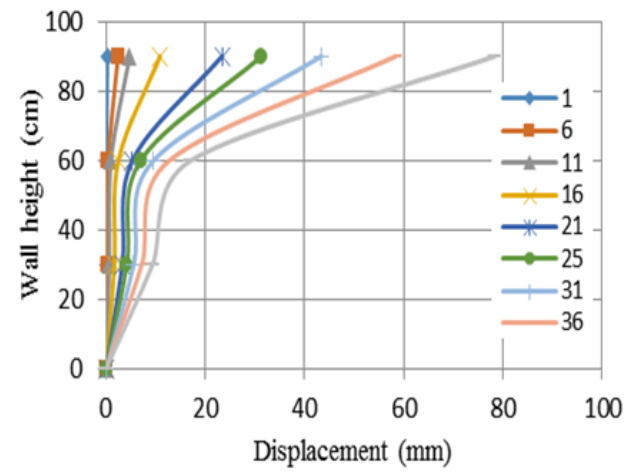

b. Specimen S2

Fig. 6. Total lateral deformation along the RC wall height for each incremental load (note: legends of curves indicate the experimental loading step) 


\section{Theoretical analysis}

The theoretical prediction analysis has been conducted using two models developed by author in a previous journal [5], i.e., detailed and simplified models as shown in Fig. 7 and Table 5. The detailed model predicts the lateral load-drift behaviour of reinforced concrete walls consisting of four stages: cracking, yield, peak, and lateral load failure which were developed using displacement based design methodology. Whereas, the simplified model comprises three stages: cracking, yield and ultimate that were developed based on classic moment-curvature approach. These models are aimed to provide simple procedures for checking lateral load-drift behaviour of non-ductile concrete walls.

The theoretical prediction of lateral load-drift behavior for all specimens S1-S3 are in good agreement with the test results as shown in Fig. 8. Generally, the theoretical models give stiffer results compared with the experimental data which is considered reasonable since the theoretical models are based only on flexural deformation analysis and does not include other deformation components. The comprehensive drift analysis are beyond the scope of this paper.

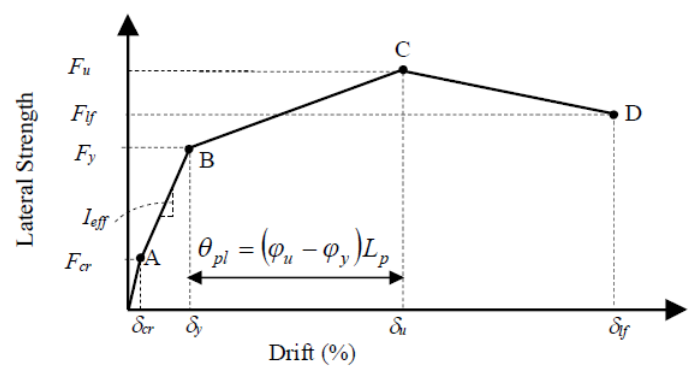

(a). Detailed model

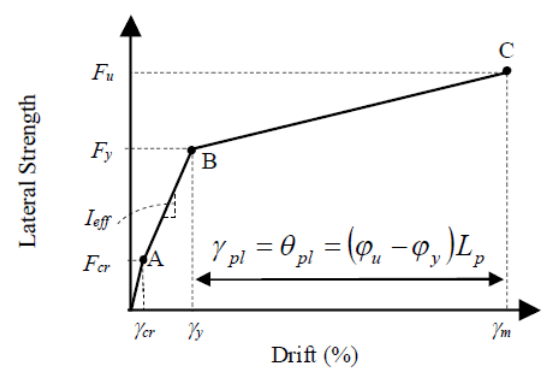

(b) Simplified Model

Fig. 7. The detailed and simplified design models of lateral load-drift capacity (refer [5])

Table 5. Analytical model procedures.

\begin{tabular}{|c|c|c|}
\hline Detailed Model & & Simplified Model \\
\hline a. Point A (Cracking) & & a. $\quad$ Point A (Cracking) \\
\hline $\begin{array}{l}F_{c r}=\frac{M_{c r}}{H_{w}} ; \gamma_{c r}=\frac{M_{c r} H_{w}}{3 E_{c} I_{g}} \\
\text { b. Point B (Yield) }\end{array}$ & (3) & $\begin{array}{l}\text { The cracked lateral strength and drift are } \\
\text { calculated by assuming cracking drift } \gamma_{\mathrm{cr}}= \\
0.1 \% \text { or calculated directly using the concrete } \\
\text { modulus and cracking strength. }\end{array}$ \\
\hline $\begin{array}{l}F_{y}=\frac{M_{y}}{H_{w}} ; \gamma_{y}=\frac{M_{y} H_{w}}{3 E_{c} I_{e}} \\
\text { c. Point C (Peak Strength) }\end{array}$ & (4) & 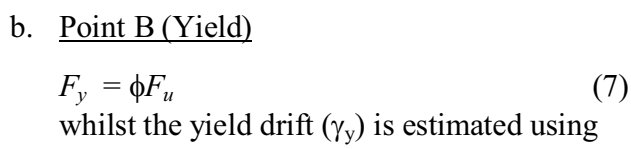 \\
\hline $\begin{array}{c}\quad F_{u}=\frac{M_{u}}{H_{w}} ; \gamma_{\text {peak }}=\gamma_{\mathrm{y}}+\gamma_{\mathrm{pl.p}} \\
\text { d. Point D (Ultimate Displacement) }\end{array}$ & (5) & $\begin{aligned} & I_{\text {eff }}=0.5 I_{g} \\
\text { c. } & \underline{\text { Point C (Ultimate) }}\end{aligned}$ \\
\hline$\gamma_{u}=\frac{\gamma_{y}}{k}\left[(1+k \alpha)-0.8 \frac{F_{u}}{V_{u}}\right]$ & (6) & $\begin{array}{l}\gamma_{\mathrm{m}}=\gamma_{\mathrm{y}}+\gamma_{\mathrm{pl}} \\
\gamma_{p l}=\theta_{p l}=\frac{W_{c r}}{L_{w}}=0.75 \frac{d_{b}}{L_{w}}\end{array}$ \\
\hline
\end{tabular}

where ; $F_{c r}=$ cracking load, $M_{c r}=$ cracking moment, $H_{w}=$ wall height, $\gamma_{c r}=$ cracking drift, $F_{y}=$ yield load, $M_{y}=$ yield moment, $\gamma_{y}=$ yield drift, $F_{u}=$ peak load, $M_{u}=$ peak moment, $\gamma_{\text {peak }}=$ drift at peak load, $\gamma_{u}=$ ultimate drift, $\gamma_{\mathrm{pl}}=$ inelastic drift, $\alpha=$ the drift ductility when the shear strength commences to decline. 

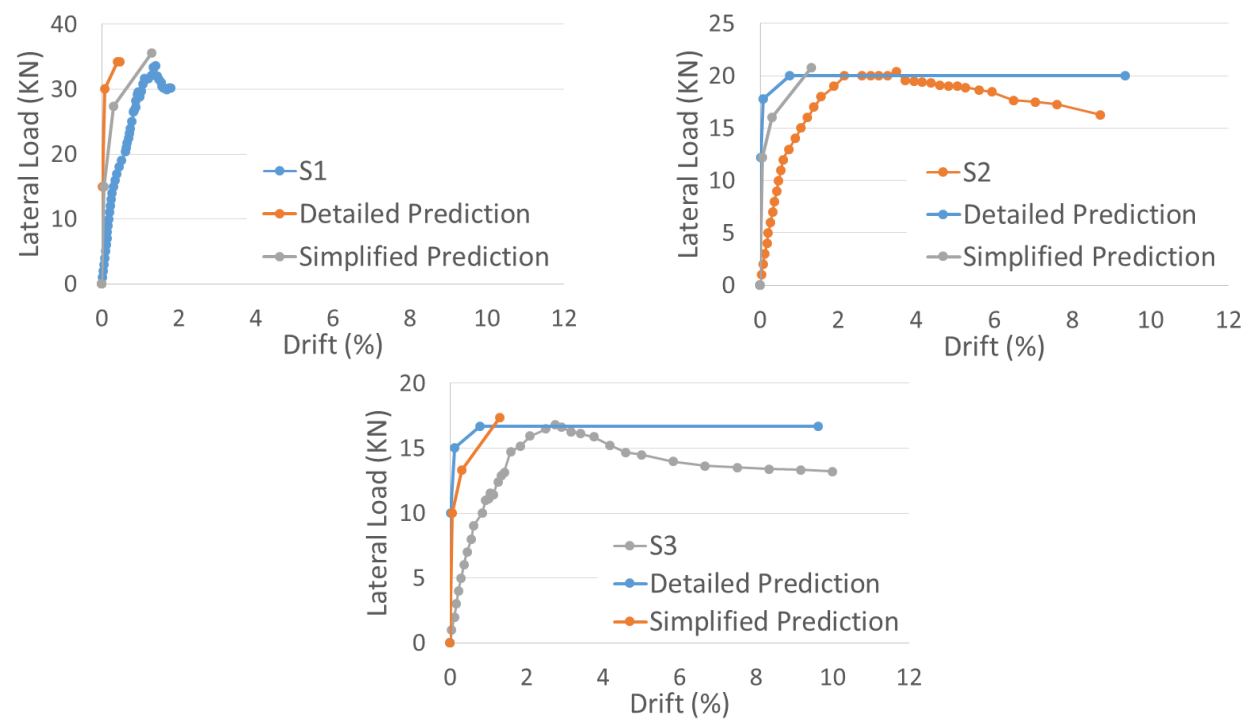

Fig. 8. Comparison of load-drift behaviour curves between experimental test and theoretical prediction results.

\section{Summary}

Three RC wall specimens have been tested to investigate seismic performance of EPS panel $\mathrm{RC}$ wall to investigate brittle-to-failure transition of wall with the outcomes as follows:

i) Squat walls (specimen S1) provided highest peak lateral load but fail in brittle manner. On the other hand, specimens S2 and S3 displayed more ductile behaviour but with smaller peak lateral loads.

ii) Shear-dominated cracks were observed on specimen S1 $(a=1.0)$ with main diagonal shear crack propagated from tip of wall to the corner of concrete compression zone at the bottom of the wall specimen. Whereas, on contrary, flexural-shear cracks occurred at both specimens S2 and S3. Interestingly, the crack zone of specimen S3 was located at the plastic hinge area of wall; whilst, for specimen S2 $(a=1.5)$ those cracks were observed at a larger extent up to the top of wall specimen. It indicates that for slender walls, the larger aspect ratio the more localised flexural cracks at plastic hinge area.

\section{References}

[1] A. Wibowo, J.L. Wilson, N.T.K. Lam and E.F. Gad, Drift capacity of precast soft storey building in Melbourne, Aust. J. Struct. Eng., 11, 3, 177-193 (2010)

[2] R. Park and T. Paulay, Reinforced concrete structures, John Wiley \& Sons, New York, USA, (1975)

[3] A. Wibowo, Seismic performance of insitu and precast soft storey buildings, $\mathrm{PhD}$ Thesis, Swinburne University of Technology, Melbourne, Australia, (2012)

[4] ASCE, Seismic rehabilitation of existing buildings, ASCE/SEI 41-06, American Society of Civil Engineers, Virginia, USA, (2007)

[5] A. Wibowo, J.L. Wilson, N.T.K. Lam and E.F. Gad, Seismic performance of lightly reinforced structural walls for design purposes, Mag. Concrete Res., 65, 13, $809-828$ (2013) 